\title{
A Study of Hybrid Composite Hydroxyapatite (HA)-Geopolymers as a Material for Biomedical Application
}

\author{
Saleha ${ }^{1,}$, Andi Riska $^{1}$, Ainun Nisa Makmur ${ }^{1}$, Fathurrakhman Ansar $^{1}$, and Subaer ${ }^{1}$ \\ ${ }^{1}$ Laboratorium Fisika Material, Jurusan Fisika, Universitas Negeri Makassar, Indonesia Jl. Daeng Tata \\ Raya, Makassar, Indonesia
}

\begin{abstract}
The main purpose of this research is to study the physical properties and microstructure characters of hybrid composites HAgeopolymers as a material for biomedical application. Hybrid composite HA-geopolymers were produced through alkaline activation method of metakaolin as a matrix and HA as the filler. HA was synthesized from eggshell particles by using a precipitation method. The addition of HA in metakaolin paste was varied from $0.5 \%, 1.0 \%, 1.5 \%$, and $2.0 \%$ relative the weight of metakaolin. FTIR was used to examine the absorption bands the composites. X-ray diffraction (XRD) was used to study the crystal structure of the starting and the resulting materials. Scanning Electron Microscopy-Energy Dispersive Spectroscopy (SEM-EDS) was used to investigate the surface morphology of the composites. The thermal properties of the samples was examined by means of Differential Scanning Calorimetry (DSC). Capacitance measurement was conducted to investigate the bioactive properties of HA. The study results suggest that hybrid composite HA-geopolymers has a potential to be applied as a biomedical such as biosensor material.
\end{abstract}

\section{Introduction}

Hybrid composite is a versatile material comprising organic-inorganic materials. This type of hybrid composite has been intensively studied including in the area of geopolymers research for various purposes [1]. One of the organic biomaterials which attract a lot of attentions lately is hydroxyapatite (HA). The chemical formula of $\mathrm{HA}$ is $\left.\mathrm{Ca}_{10}\left(\mathrm{PO}_{4}\right)_{6}(\mathrm{OH})_{2}\right)$ and it is a compound that formed the constituent of tissues in the human body such as bones and teeth [2]. HA which can be applied as synthetics bones synthesize from materials containing high calcium, such as cows bone, seashell and eggshell [3]. Eggshell for instance consist of $94 \% \mathrm{CaCO}_{3}, 1 \% \mathrm{MgCO}_{3}, 1 \% \mathrm{CaPO}_{4}$ [4]. Recently, $\mathrm{HA}$ was synthesized by using sol-gel or precipitation method $[5,6]$. HA possesses biocompatible properties and has a reasonable high compressive strength [7]. However, HA is a brittle material like

* Corresponding author: saleha.alimuddin@gmail.com 
ceramics hindering this material from wide range applications and mostly used as a biomaterial for low pressure application [8]. The properties of HA can be improved by combining with other material and form a composite like structure.

Hule, et.al., [9] reported that the nanocomposite hydroxyapatite-etilen-vinyl acetate (HAp-EVA) has a flexural strength and elongation which higher than a single particle of hydroxyapatite, and it can be used as matrix of bones regeneration. Chia-Jung, et.al., [10] showed that silicate polymer nanocomposite which synthesized by using HA as an aggregate changed the structure, modulus, strength and toughness of HA [10].

This research was conducted to synthesize and examine the properties of hybrid composite made from geopolymers and HA. Metakaolin, an amorphous mineral produced from hydroxylated kaolin at temperature between $600-750^{\circ} \mathrm{C}$, was used as inorganic material to produce geopolymers paste which act as a binder (matrix) and hydroxyapatite (HA) which synthesized from eggshell as organic fillers. The geopolymers paste produced was categorized as poly(sialate-siloxo) [11].

\section{Experimental}

Hybrid composite HA-geopolymers were produced through alkaline activation of metakaolin. HA was synthesized from eggshell by using a precipitation method. The eggshell was grounded and sieved to obtain fine particles. The resulting particles was calcined at $750^{\circ} \mathrm{C}$ for 2 hours followed by precipitation process by using Na3PO4, NH3, and $\mathrm{HCl}$ solutions. The resulting material was dried at $110 \mathrm{oC}$ for 12 hours and then calcined again at $750 \mathrm{oC}$ to obtain hydroxyapatite particles. The composites were produced by added geopolymer paste with HA varying the weight percentage of HA $0.5 \%, 1.0 \%$, $1.5 \%$ and $2.0 \%$ relative to the weight of metakaolin. The mixtures were stirred manually, molded and then cured at $60^{\circ} \mathrm{C}$ for 1 hour.

The functional groups of hybrid composite HA-geopolymers were studied by means of Fourier Transform Infra Red (FTIR). The phase and the structure of the starting materials and produced hybrid composite HA-geopolymers were examined by using X-ray Diffraction (XRD). Scanning Electron Microscopy-Energy Dispersive Spectroscopy (SEMEDS) was used to study the morphology of the surface of the sample as well as the interface between geopolymer matrix and HA particles. The thermal properties of the samples was studied by using Differential Scanning Calorimetry (DSC). Capacitance measurement was conducted to investigate the bioactive properties of the composites.

\section{Results and discussion}

Fig. 1 showes the representative samples produced in this study. Figure 1(a) shows the appearance of geopolymers without HA. Fig. 1(b) shows hybrid composite of HAgeopolymers having different compositions of HA. 


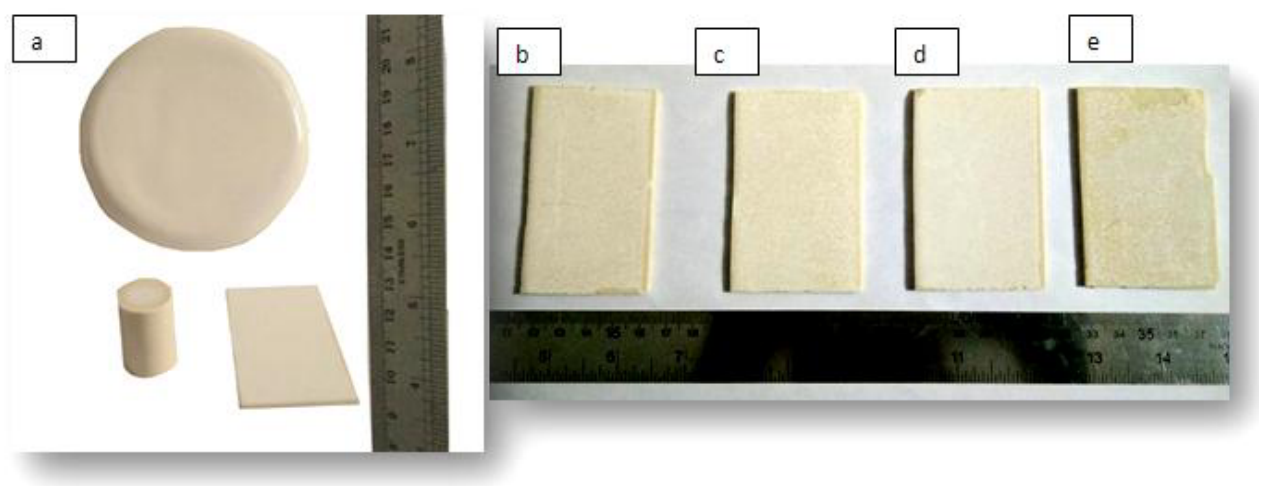

Fig. 1. Hybrid composite HA-Geopolymers (a) geopolymer without HA; (b) $0.5 \%$ HA; (c) $1.0 \%$ HA; (d) $1.5 \%$ HA, (e) $2.0 \% \mathrm{HA}$.

Fig. 2 shows the IR bands of pure geopolymer ( $0 \%$ HA) and geopolymer added with $2 \%$ of HA. The IR spectrum of pure geopolymer is typical with a band at $3398 \mathrm{~cm}^{-1}$ and $1649 \mathrm{~cm}^{-1}$ which is due to absorbed atmospheric water. A strong band for $\mathrm{Si}-\mathrm{O}$ stretching was found at $977 \mathrm{~cm}^{-1}$ which is a bit lower than that of metakaolin $\left(1050 \mathrm{~cm}^{-1}\right)$. This is due to tetrahedra condensation of geopolymer. The $\mathrm{Si}-\mathrm{O}-\mathrm{Al}$ bond was observed between 680 $\mathrm{cm}^{-1}-875 \mathrm{~cm}^{-1}$ indicating the reaction between alkali solution and solid Al-O sheet in metakaolin. The absorption bands of $\mathrm{CaO}$ was found at $1381 \mathrm{~cm}^{-1}$ for geoplymer without $\mathrm{HA}$, and at $1437 \mathrm{~cm}^{-1}$ and $1458 \mathrm{~cm}^{-1}$ for geopolymers with $2 \mathrm{wt} \%$ and $4 \% \mathrm{HA}$, respectively. The shift of $\mathrm{Cao}$ bands is due to the high content of $\mathrm{CaO}$ in $\mathrm{HA}$.

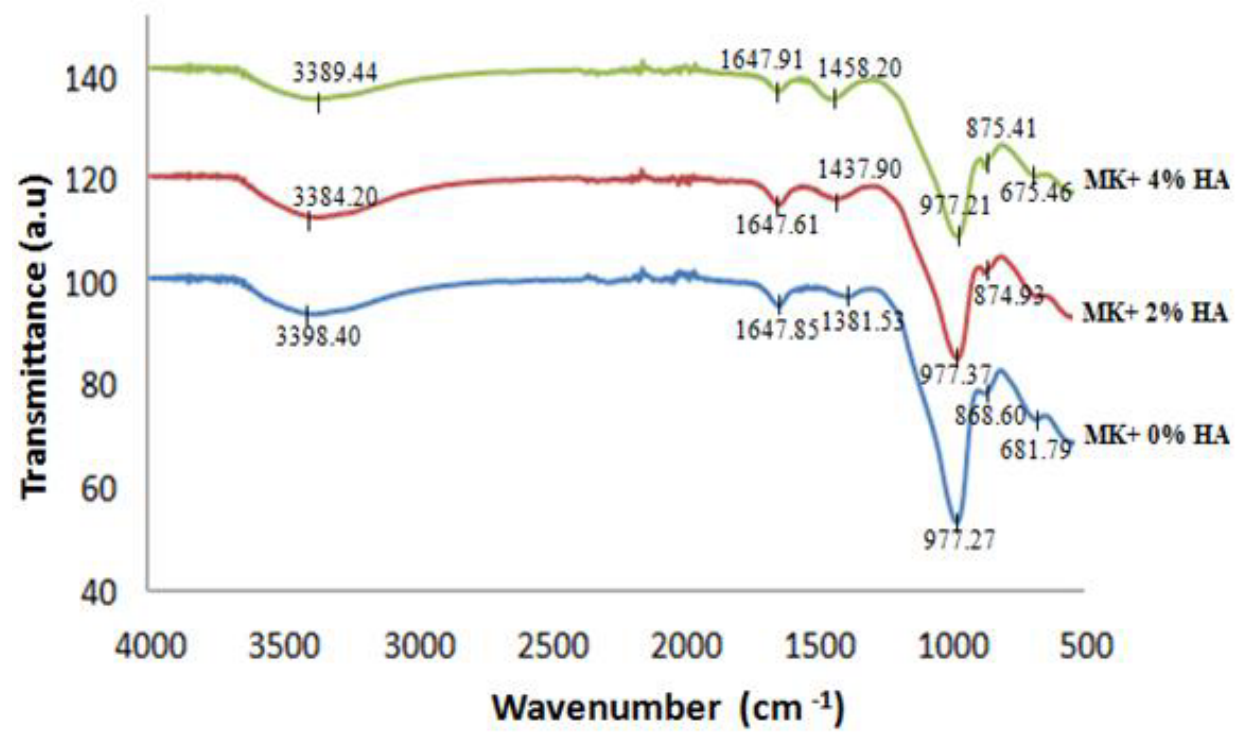

Fig. 2. FTIR Spectra of geopolymer ( $0 \% \mathrm{HA})$ and hybrid HA-geopolymers.

Fig. 3(a) shows the diffractogram of hydroxyapatite precursor and alkali activated hydroxyapatite. The diffraction patterns show that HA has a high level of crystallinity alongside with $\mathrm{CaO}$ and $\mathrm{Ca}(\mathrm{OH})_{2}$ crystals. Fig. 3(b) shows the SEM image of the activated hydroxyapatite which formed a well-structured crystals. Based on the XRD examination, 
the content of $\mathrm{CaO}$ and $\mathrm{Ca}(\mathrm{OH})_{2}$ increase while the weight percentage of HA decrease. This indicates that HA reacts with alkaline solution. Fig. 3(b) shows the SEM image of hydroxyapatite activated with alkaline solution. These results indicate that HA and geopolymer paste will form a strong chemical bond as they both can be activated by alkaline solution and hence creates hybrid II composite.

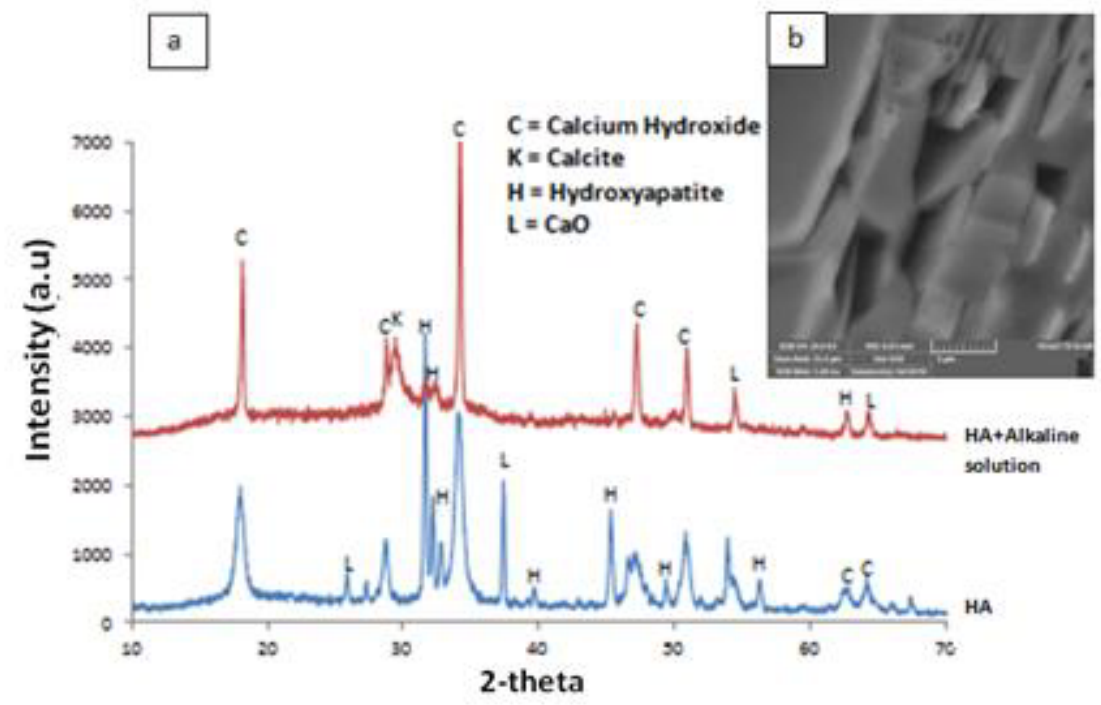

Fig. 3. (a) Diffractogram of HA and alkali activated HA, (b) SEM image of alkali activated HA.

Table 1 shows the phase composition of hydroxyapatite (wt \%) measured with XRD. It can be seen that the eggshell produced in this research reached $47 \mathrm{wt} \%$ of $\mathrm{HA}$ and $46 \mathrm{wt} \%$ $\mathrm{Ca}(\mathrm{OH})_{2}$. The alkali activated $\mathrm{HA}$ produced a material that rich with $\mathrm{Ca}(\mathrm{OH})_{2}$ and $\mathrm{CaCO}_{3}$, reducing the $\mathrm{wt} \%$ of $\mathrm{HA}$ and $\mathrm{CaO}$.

Table 1. The composition of HA and alkali activated HA (wt $\%)$.

\begin{tabular}{|c|c|c|}
\hline \multirow{2}{*}{ Phase } & \multicolumn{2}{|c|}{ Sample } \\
\cline { 2 - 3 } & HA & $\begin{array}{c}\text { HA+Alkaline } \\
\text { solution }\end{array}$ \\
\hline $\mathrm{Ca}_{5}\left(\mathrm{PO}_{4}\right)_{3}(\mathrm{OH})$ & 47,0 & 6,9 \\
\hline $\mathrm{CaCO}_{3}$ & 0,3 & 33 \\
\hline $\mathrm{CaO}$ & 6,6 & 0,2 \\
\hline $\mathrm{Ca}(\mathrm{OH})_{2}$ & 46,0 & 60 \\
\hline
\end{tabular}

Fig. 4 shows the diffractogram of hybrid composites HA-geopolymers along with the diffractogram of HA and metakaolin. A broad hump of diffraction patterns between $20-$ $40^{\circ} 2 \theta$ indicate the amorphous nature of geopolymers. The addition of $2 \mathrm{wt} \%$ HA relative to the weight of metakaolin did not change the amorphous phase of geopolymers. Quartz mineral originated from metakaolin remains on the network of geopolymer although its peak slightly decreases as the content of HA increases. 


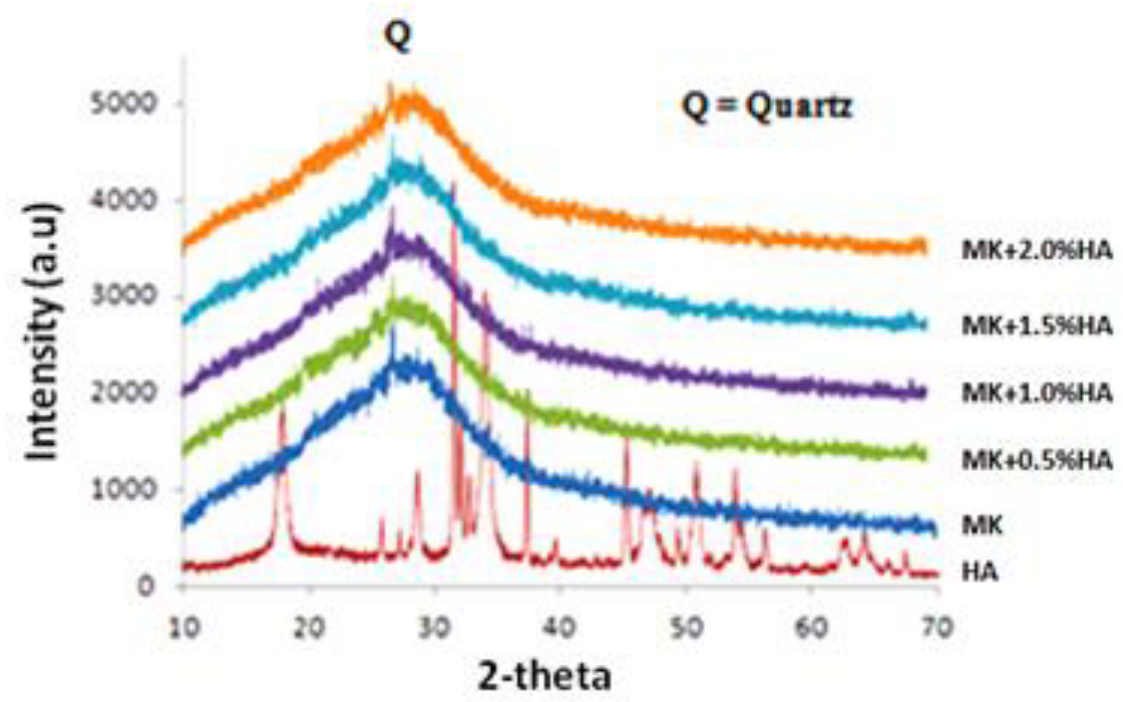

Fig. 4. Diffractogram patterns of HA, metakaolin and four samples of hybrid composites.

Fig. 5 shows the SEM images of metakaolin, HA, and hybrid composites produced in this research. The metakaolin particles (5a) appear to retain the flake shape of kaolinite crystallinity. The morphology of HA particles tend to form a hexagonal shape with a size between $5-10 \mu \mathrm{m}$ similar to that reported in $[12,13,14]$. HA tends to form agglomerates with an average size of crystals in the range of 15-50 nm [15] as well as irregular morphology [16]. Fig. 5 (c), (d), (e), and (f), show the morphology of hybrid composite HA-Geopolymers. It can be seen that the matrix of geopolymer form a strong chemical bond with HA particles confirming the formation of hybrid type II. Fig. 5(d) and (e) show some unreacted of metakaolin particles during the polymerization.

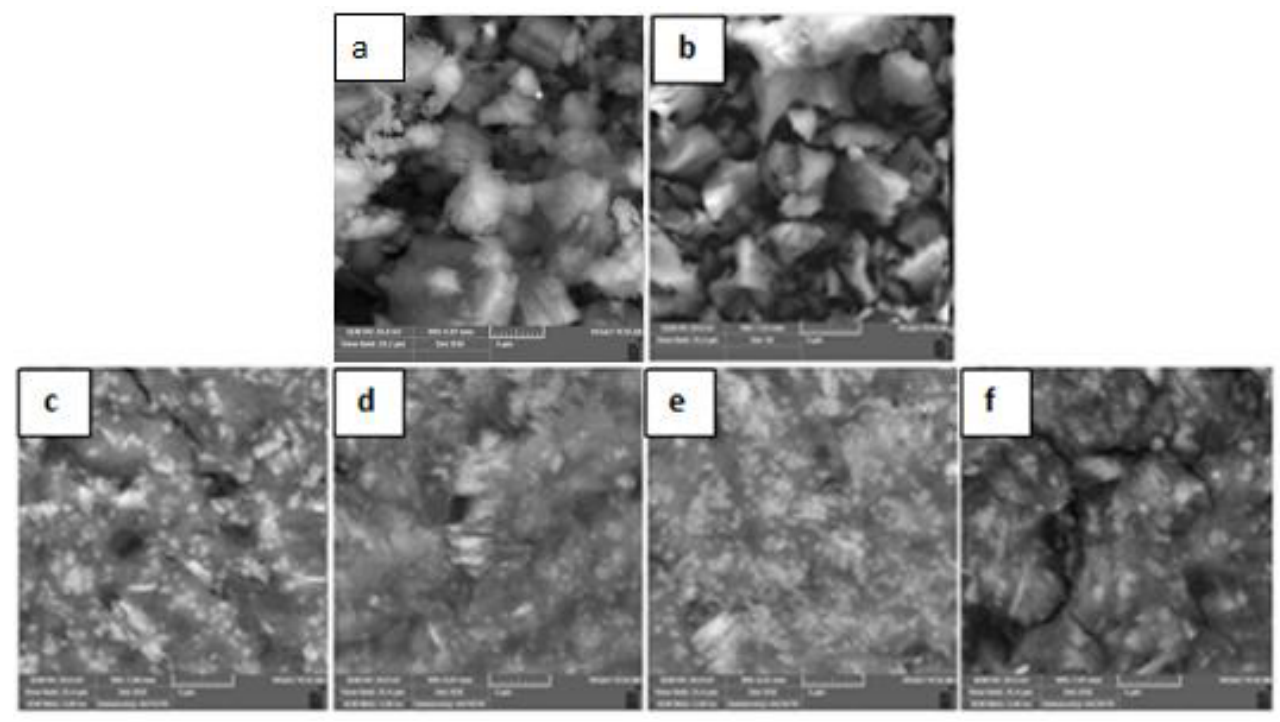

Fig. 5. SEM images (a) metakaolin, (b) HA, (c) metakaolin + HA 0.5\%, (d) metakaolin + HA $1.0 \%$, (e) metakaolin + HA $1.5 \%$, (f) metakaolin + HA $2.0 \%$. 
Fig. 6 shows the results of DSC measurements for as-prepared hybrid composite HAgeopolymers (a) and hybrid composite HA-geopolymer cured at $60^{\circ} \mathrm{C} / 1$ hour. The measurements were conducted at the temperature range between $30-400^{\circ} \mathrm{C}$ with a heating rate $20^{\circ} \mathrm{C} /$ minute. The presence of $\mathrm{HA}$ in geopolymer network reduced the exothermic peak as well as the enthalpy of the composites before and after curing (Table 2). It was also observed that the exothermic peak and enthalpy of pure geopolymer were higher than those of geopolymer with HA addition. This results point out that the capacity of geopolymer to absorb or release heat is higher than that of hybrid composite HA-geopolymers.
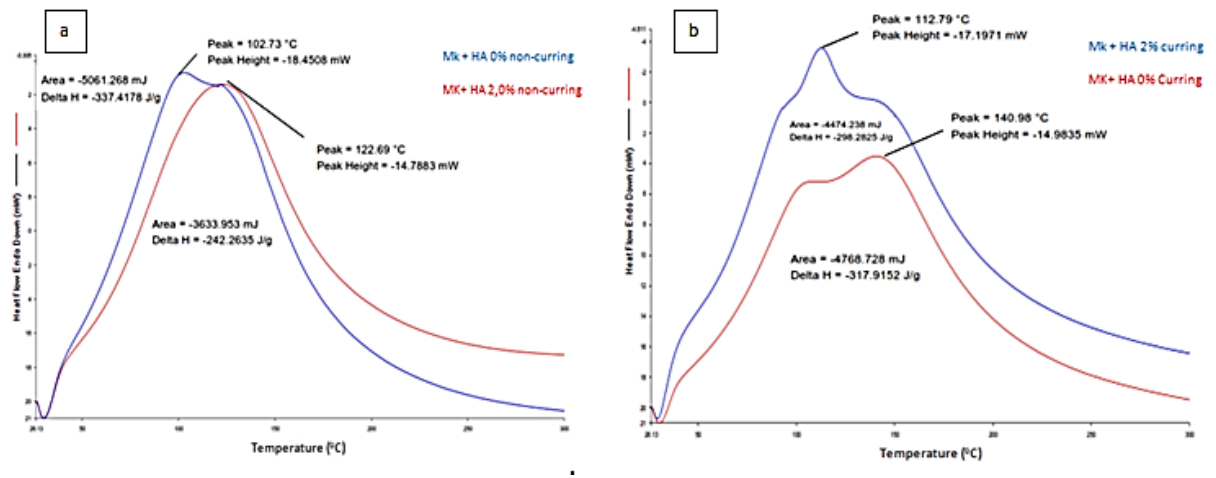

Fig. 6. DSC results of (a) as-prepared samples, (b) cured samples.

Table 2. DSC analysis of pure geopolymer and hybrid composite HA-geopolymer.

\begin{tabular}{|l|l|l|l|l|}
\hline Nama Samples & $\operatorname{Onset}\left({ }^{\circ} \mathrm{C}\right)$ & Peak $\left({ }^{\circ} \mathrm{C}\right)$ & $\operatorname{End}\left({ }^{\circ} \mathrm{C}\right)$ & Delta H $(\mathrm{J} / \mathrm{g})$ \\
\hline Pure geopolymer paste & 35.75 & 102.73 & 180.66 & 337.4178 \\
\hline Pure Composite (HA 2\%) & 60.17 & 122.69 & 185.65 & 242.2635 \\
\hline Cured geopolymer & 55.24 & 140.98 & 207.77 & 317.9152 \\
\hline Cured Composite (HA 2\%) & 58.70 & 112.79 & 171.29 & 298.2825 \\
\hline
\end{tabular}

Fig. 7 shows that the dielectric properties of hybrid composites as a function of $w t \%$ HA and the thickness of the sample conducted by using capacitance measurement. The results indicate that the magnitude of samples capacitance is directly proportional to the weight of HA and hence the thickness of the samples. This results prove that the hybrid composite HA-geopolymer exhibit a bioactive properties [17, 18]. The results also suggest that use of geopolymers to bind HA do not reduce the bioactive properties of HA and therefore can be applied as biosensor [19,20]. 


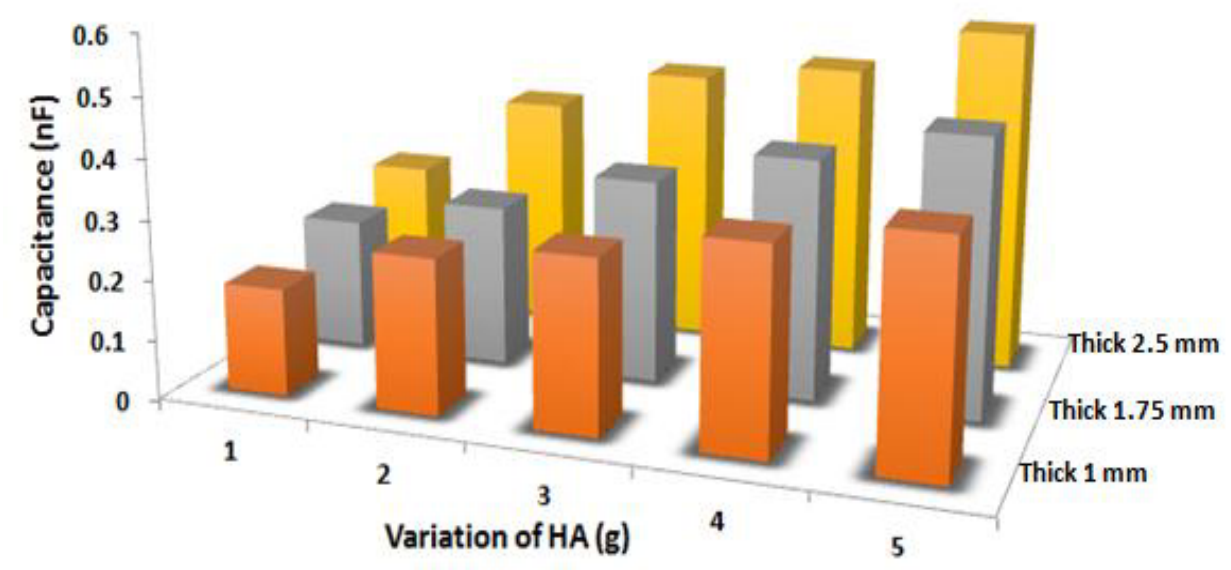

Fig. 7. The relation between capacitance capacitive and the variation of HA.

\section{Conclusion}

Hybrid composites hydroxyapatite (HA)- geopolymers based on metakaolin have been successfully produced. The FTIR and XRD analysis shows that the addition of HA did not affect the overall absorption bands and the amorphous phase of geopolymer. SEM examination reveal good chemical bond between HA particles with geopolymer matrix indicating strong mechanical properties. DSC results indicate that the presence of HA reduce the capacity of geopolymer to absorb or release heat from the interior of geopolymers. The dielectric properties of hybrid composite HA-geopolymers based on capacitance measurement showed that this composite has a potential to be applied as biosensor material.

\section{References}

1. R. Giuseppina, R. Laura, F. Claudio, C. Francesco, C. Raffaele, T. Oreste, Materials, 6 (2013)

2. S. Vikramjit, M. Neeraj, Internatinonal Journal of Science and Engineering Investigations, 1 (2012)

3. S.T. Wahyudi, S.U. Dewi, A. Anggraeni, K. Dahlan, Akhmaloka, M.A. Zulfikar, R. Hertadi, Adv. Mat. Res., 896 (2014)

4. S.M. Fabio, O.R. Patrik, M.T. Celia, A.S.S. Marcos, Food Sci. Technol. (Campinas), 27 (2007)

5. M.S. Mazrooei, M.H. Fathi, Ceram. Int., 38, 2012.

6. I. Mobasherpour, M.S. Heshajin, A. Kazemzadeh, M. Zakeri, J. Alloys. Compd., 430 (2007)

7. P. Triyunda, B.W. Haris, R.Z. Andi, Solids and Structures, 1 (2012)

8. J. Luan, S. Wang, Z. Hu, L. Zhang, Curr. Org. Synth., 9 (2012)

9. A. Hule, J. Pochan, Darrin, Mrs. Bull., 32 (2007)

10. W. Chia Jung, K.G. Akhiles, Gaharwar, Materials, 3 (2010)

11. Subaer, Pengantar Fisika polimer. Jakarta: DP2M Dikti (2007)

12. K.B. Ravi, E.J.P. Gerrard, F. Derek, American Journal of Materials Science, 4 (2013) 
13. G. Taglieri, C. Mondelli, V. Danieli, E. Pusceddu, G. Scoccia, Advances in Materials Physics and Chemistry, 4 (2014)

14. Taglieri, C. Mondelli, V. Danieli, E. Pusceddu, G. Scoccia, Advances in Materials Physics and Chemistry, 3 (2013)

15. P. Hui, S.L. Meena, G. Singh, R.D. Agarawal, S. Prakash, Journal of Minerals and Materials Characterization and Engineering, 8 (2010)

16. C.M. Luis, L.R. Geysy, C.M. Raphaella, Materials Sciences and Applications, 3 (2012)

17. P.N. Lim, E.Y. Teo, B. H0, B.Y. Tay, E.S. Thian, J. Biomed. Mater. Res. A., 101A (2013)

18. G. Tetteh, A.S. Khan, R.M. Delaine Smith, G.C. Reilly, I.U. Rehman, J. Mech. Behav. Biomed. Mater., 39 (2014)

19. I. Sporysh, E. Shynkaruk, O. Lysko, A. Synkaruk, Mater. Sci. Eng., B, 169 (2010)

20. H. Li, Y. Liu, L. Luo, Y. Tan, Q. Zhang, K. Li, Mater. Sci. Eng., C, 59 (2015) 